\title{
"Sólo interesados en los muertos". Representaciones mediáticas nacionales y narrativas de los habitantes de la frontera Ecuador-Colombia
}

\author{
Mauro CERBINO \\ mcerbino@flacso.edu.ec \\ Universidad Nacional de Cuyo (Ecuador) \\ Isabel RAmos \\ iramos@flacso.edu.ec \\ Universidad Nacional de Cuyo (Ecuador) \\ Ana RodRÍGUEZ \\ anacrodriguez@fmcquito.gob.ec \\ Fundación Museos de la Ciudad del Municipio de Quito (Ecuador)
}

Recibido: 24 de enero de 2014

Aceptado: 9 de septiembre de 2014

\section{Resumen \\ El artículo examina las representaciones de la prensa gráfica ecuatoriana sobre la población de la fron- tera Norte, en el marco de las relaciones entre los gobiernos de Ecuador y Colombia, así como la cons- trucción local de alternativas frente a las mismas. A partir de una mirada que combina etnografía y análisis del discurso, se da cuenta del papel de los medios en la construcción y reproducción de imágenes reper- cuten negativamente en la vida cotidiana en frontera. Además, se constata la existencia de narrativas y prácticas locales que podrían ser consideradas intentos de reapropiación de la producción informativa por parte de la población fronteriza. Las entendemos como esfuerzos por recuperar el protagonismo y la ca- pacidad de decidir sobre qué decir, cómo hablar y a quiénes consultar sobre la frontera. \\ Palabras clave: frontera, representación, medios de comunicación, seguridad, enclave. \\ "Only Interested in the Dead". National Media Representations and Narratives of the People of the Ecuador-Colombia Border}

\begin{abstract}
The article examines representations of Ecuadorian newspapers on northern border population, in the framework of relations between the Governments of Ecuador and Colombia. It also addresses how to build local alternatives toward such representations. From a look that combines ethnography and discourse analysis, we observe the role of media in the construction and reproduction images that adversely affect daily life in this border. Moreover, the existence of local narratives and practices that could be considered attempts to reappropriate this production by the border population is found. We understand them as efforts to regain ownership and the ability to decide on what to say, how to talk and who to ask about the border.
\end{abstract}

Keywords: border, representation, media, security, enclave.

\section{Referencia normalizada}

CERBINO, Mauro; RAMOS, Isabel; y RODRÍGUEZ, Ana (2015): “«Sólo interesados en los muertos». Representaciones mediáticas nacionales y narrativas de los habitantes de la frontera Ecuador-Colombia". Estudios sobre el Mensaje Periodístico. Vol. 21, Núm. 1 (enero-junio), págs.: 251-268. Madrid, Servicio de Publicaciones de la Universidad Complutense.

Sumario: 1. Introducción. 2. Un breve estado de la cuestión. 3. Método de estudio. 4. Análisis y resultados; 4.1. La frontera en las agendas mediáticas nacionales, provinciales y locales; 4.2. La prensa na- 
cional: de espaldas a la población fronteriza; 4.3. Narrativas locales y representaciones mediáticas; 4.4. El enclave de producción de noticias sobre la frontera; 4.5. Localización y heterotopía en la frontera: algunas reflexiones teóricas. 5. Conclusiones. Estereotipo fronterizo y conformación de la opinión pública. 6. Referencias bibliográficas.

\section{Introducción}

La investigación da cuenta de la divergencia entre las representaciones de los medios gráficos nacionales y hegemónicos sobre frontera, y las autorepresentaciones de las personas y organizaciones que la habitan. Se intenta interpretar las razones de esta divergencia, considerando la presencia de una agenda mediática por la cual los modos de representación de la frontera se adecuan a imperativos hegemónicos nacionales e internacionales, mientras que, por el lado de los habitantes, se ponen en juego otras formas de representación, vinculadas con la reproducción cotidiana y social.

El artículo quiere contribuir a mostrar las implicaciones de esta divergencia, en términos del papel que juegan los medios nacionales en el supuesto compromiso según las ideas liberales clásicas- que tienen los mismos de reducir la complejidad (Luhmann, 1998) y familiarizar a la sociedad respecto a fenómenos que acontecen en lugares distantes de los grandes centros urbanos. En este caso, los medios no solo incumplen con esta tarea, sino que distorsionan la información, en la medida en que no recogen las experiencias y representaciones que los habitantes de la frontera tienen de sus vidas y entorno.

La agenda de los medios nacionales estaría determinada por una larga tradición de guerra y militarización de fronteras, que expresa una disputa por la legitimidad de las políticas de uno y otro estado con respecto a un tercero que busca imponer su voluntad; en este caso, un orden transnacional, representado por los Estados Unidos y las empresas multinacionales extractivas, mineras y palmicultoras especialmente. Esta agenda se ha construido históricamente en otro lugar que no es la frontera propiamente dicha. La misma supone representar un modo de vida que es pensado bajo la influencia de interpretaciones canónicas en torno al conflicto, lo transnacional y la soberanía. La frontera se constituye, para los medios, en un caso ejemplar para sostener los argumentos de su agenda, teniendo en cuenta que, para la mayor parte de la población del resto del país, las fronteras son espacios desconocidos y misteriosos.

La tensión entre las autorepresentaciones de los habitantes fronterizos y las representaciones hegemónicas de los medios es, a nuestro entender, una disputa por modelos ideológicos, por la noción misma de soberanía y de regionalidad, que no se vincula únicamente a los territorios fronterizos y que evidencia, además, otros procesos de reproducción sociocultural. Los habitantes de la frontera norte absorben el conflicto armado colombiano como una condición propia, y generan formas de identidad ligadas a la inestabilidad, a la movilidad y a la clandestinidad que resultan particularmente interesantes.

La particularidad con la que el conflicto es vivido en frontera no aparece en los medios de comunicación. Por su característica de liminalidad la frontera tiende a ser representada por los medios expresando y velando al mismo tiempo agendas ocultas e ideológicas. Por ello, la frontera se vuelve ejemplar para descifrar los modos ideológicos con los que los medios nacionales construyen la información. 
Por medio del análisis mediático se pueden descifrar algunos elementos de los modelos de representación empleados por los medios gráficos nacionales, en los que se dan cuenta de agendas temáticas no siempre explicitadas alrededor de conflictos sociales y ambientales ligados a la fronterización y el enclave, la explotación de recursos naturales, y a temáticas de seguridad como el contrabando, el terrorismo y el narcotráfico.

En este contexto, la frontera que aparece en los medios asume la característica de un lugar espontáneamente violento. La violencia es naturalizada por la propia condición del espacio fronterizo, como si se tratara de un lugar que por su situación limítrofe está destinado a ser violento. Al intentar representar la frontera, el criterio casi único de lo mediatizable es la violencia.

En sus coberturas sobre la frontera colombo-ecuatoriana, los medios no aportan información que permita pensar en los fundamentos estructurales de la violencia y, más bien, contribuyen a sostener la idea de su generación espontánea. Dado que no se aportan razones que permitan entender la violencia, sostenemos que la condición de ininteligibilidad estructural constituye una mayor violencia de parte de los medios hacia las poblaciones fronterizas.

En oposición a esta perspectiva mediática, en el presente trabajo consideramos las fronteras no como lugares naturales, sino como construcciones culturales e históricas, de las que participan fundamentalmente los estados y la población que las habita. Estas construcciones, siempre contingentes, se reproducen socialmente en un espacio que se representa como un mundo de la vida, constituido como diría Habermas, por el escenario de encuentros simbólicos e intersubjetivos, donde los sujetos construyen sentidos de realidad.

Siendo lugares de tránsito y de intensos intercambios simbólicos, las fronteras se constituyen a través de lo que Grimson ha denominado fronterización, procesos históricos "construidos por los poderes centrales y por las poblaciones locales". Por lo tanto, la frontera nunca es un dato fijo, sino un objeto inacabado, constantemente disputado por interpretaciones diversas. "Un objeto que, como producto histórico de la acción humana puede ser -y es- reestructurado y resignificado" (Grimson, 2003: 17). Los procesos de fronterización, suponen etapas históricas marcadas por la coyuntura local, nacional e internacional, que necesariamente inciden en la organización de las sociedades de frontera. En cada etapa se articulan de diversas maneras un conjunto de intereses económicos y políticos, a partir de los cuales la población fronteriza se organiza y construye sus relaciones y reivindicaciones hacia adentro y hacia afuera del límite territorial.

El análisis de los vínculos de los ecuatorianos con el otro lado -de la fronterasegún la denominación reiterada localmente, debe considerar los elementos constitutivos de la socialidad que son las relaciones y prácticas que las poblaciones fronterizas de Colombia y Ecuador construyen en común, sus encuentros y desencuentros, acuerdos, negociaciones y enfrentamientos, las cuales producen situaciones de frontera (Grimson, 2003), cuyo carácter complejo resulta indispensable reconocer en el momento de pensar el papel de la prensa en estas zonas.

Por ello, investigar una frontera exige pensar cómo es cotidianamente producida, recreada y reproducida por los diferentes agentes sociales que intervienen en ese es- 
pacio; en el caso de la presente investigación, dichos agentes están constituidos por los medios de comunicación, los periodistas locales, los corresponsales de medios nacionales, los miembros de las organizaciones sociales y las autoridades locales.

El estudio que presentamos intenta analizar la manera en que las condiciones de la construcción de la información periodística nacional y local afectan las representaciones sobre lo local, y al mismo tiempo ponen al descubierto el problema de la producción informativa, sus prácticas y limitaciones. La reversión de estos procesos posibilitaría el despliegue de potencialidades para la producción de otras representaciones y significantes que apunten a narrar y valorar formas de vida locales, más allá de intereses estratégicos y prioridades internacionales, nacionales y mediáticas.

\section{Un breve estado de la cuestión}

Los estudios en el campo de las ciencias de la comunicación que analicen teóricamente la articulación entre medios masivos y fronteras resultan escasos. Sin embargo, podría afirmarse que desde las ciencias sociales y particularmente desde el pensamiento decolonial, la frontera podría ser ubicada como un espacio otro entre aquellos considerados periféricos o subalternos, en los que prevalecería un estado de naturaleza por sobre la cultura y la historia, un espacio que solamente puede ser pensando desde categorías que afianzan la idea de lo atrasado y de lo bárbaro, y de esta manera la constitución de saberes que aseguren el dominio de los poderes nacionales, internacionales y globales, sobre el territorio y sus habitantes (Coronil, en Lander, 2000).

Para Grimson (2003: 19), una situación de frontera se constituye por un encuentro que supone que, además de la intervención de los poderes estatales, expresada en leyes, reglamentos y acciones diversas, la frontera se defina por las prácticas de quienes la habitan. Este enfoque subraya la consideración de las representaciones de los habitantes y de lo local, como aspecto que determina la construcción de la frontera.

En otro trabajo (Linares, 2009), el mismo autor analiza el papel de los medios en la construcción de la frontera entre Argentina y Paraguay, como punto de referencia a partir del cual se representan sentidos de solidaridad y fraternidad entre los dos países, pero también diferencias culturales e identidades que pueden asumir formas conflictivas, produciendo contrastes entre una ciudad fronteriza supuestamente "cosmopolita" (la argentina), y una ciudad fronteriza supuestamente "atrasada" (la paraguaya). Según Grimson, cuando se producen conflictos, los medios se parcializan en posiciones nacionalistas, y tienden a asumir un protagonismo que los convierte en instrumentos culturales y políticos de una disputa internacional, contribuyendo incluso a profundizar dichos conflictos.

Por su parte, Giménez (2007) quien realiza un análisis de la frontera entre México y Estados Unidos, a partir de los mapas mentales construidos a ambos lados de la frontera, parte de la hipótesis según la cual "la frontera realmente existente y operante es la frontera representada y vivida (a veces contradictoriamente) por los actores sociales situados de uno y otro lado de la misma" (Giménez, 2007: 2). Mientras que el territorio es el área geográfica donde un grupo ejerce poder, la frontera marca una discontinuidad, un modo distinto de organizar un territorio y de usarlo en términos materiales y simbólicos. El autor establece una distinción fundamental entre frontera 
como border y como franja fronteriza: "La frontera es simplemente una línea políticoadministrativa que se mide en términos de longitud, pero no de anchura. La franja fronteriza, en cambio, es un territorio" (Ídem, 20). Entonces, la realidad geográfica es una realidad interna y no visible, hecha de las representaciones que los individuos tienen sobre su territorio, y que, aunque prescinda de la totalidad, les sirve para orientar sus decisiones (Ídem, 22). Los medios de comunicación tienen un papel capital en la construcción de estas representaciones: los hechos y sucesos narrados a partir de los mapas mentales de los mexicanos, son aquellos que han tenido mayor difusión mediática, así lo afirman testimonios de los sujetos entrevistados. Como indica el autor, se configura, de este modo, en las sociedades de frontera, un "presentismo" -concepto de Castoriadis- según el cual las sociedades se caracterizan por vivir un presente de inmediatez, construido mediáticamente (Ídem, 31).

Para Valenzuela Arce (2000), las representaciones sobre la frontera han estado fuertemente definidas desde prejuicios y estereotipos, lo que ha determinado "diversos ámbitos de desencuentro social y cultural, a partir de los cuales se reproducen los elementos que otorgan visos de credibilidad a los prejuicios" (Ídem, 57). A través de un análisis de la industria cinematográfica mexicana y estadounidense, este autor estudia la generación de estereotipos de las fronteras como lugares de conflicto, donde confluyen todos los males conocidos y determinados en las sociedades, de modo que las fronteras quedan definidas como "zonas problema".

Al inicio de la década de los 90, la investigación sobre fronteras en Ecuador destacó las repercusiones del narcotráfico en las zonas limítrofes con Colombia (Bagley et al, 1991; Bonilla, 1993), generando una reflexión y discusión que trascendió el espacio académico y aún alimenta la agenda de seguridad en la región andina. A este respecto y con una mirada crítica, en una parte de su investigación sobre seguridad, que tiene en cuenta los procesos fronterizos, Rivera analiza cómo los medios masivos conducen prácticas y representaciones sociales del Estado y de otros actores hacia la opinión pública, la misma que se posiciona sobre determinados temas -como la inmigración forzada- por medio de las figuras discursivas mediáticas. El autor sostiene que la migración forzada es estigmatizada por los mass media a través de la consolidación de estereotipos que permiten la defensa frente a las supuestas amenazas, y el control de la vulnerabilidad (Rivera, 2012). Los medios ecuatorianos han contribuido a una construcción discursiva de los inmigrantes, que ha pasado desde una posición tolerante hacia lo colombiano hacia posiciones discriminantes y nacionalistas que estigmatizan a esa población (Ídem).

Más allá de las diversas definiciones de frontera, la literatura muestra distancia existente entre las formas de representación de las fronteras por parte de los medios, y aquellas representaciones que podríamos llamar diversas, que tienen relación con el conocimiento local; da cuenta sobre todo, del papel de los medios en la construcción de imágenes estigmatizantes y conflictivas, que distan de ser ingenuas a la hora de analizar sus influencias en las representaciones sociales y políticas que sustentan tomas de decisiones, y que por su carácter de meras simplificaciones de la realidad, resultan muchas veces negativas para los habitantes fronterizos. 


\section{Método de estudio}

La investigación se realizó a través de métodos etnográficos y análisis de contenido. En cuanto al estudio etnográfico, se analizaron los sentidos y significados que los actores sociales locales y medios de comunicación construyeron a través de sus directores, editores, periodistas y lectores.

La información de campo fue obtenida mediante seis talleres de discusión realizados en Esmeraldas, Carchi y Sucumbíos, las provincias ecuatorianas limítrofes con Colombia. Estas actividades convocaron a 119 periodistas, dirigentes comunitarios, integrantes de organizaciones sociales y autoridades civiles. Adicionalmente, se efectuaron 18 entrevistas en profundidad con investigadores y académicos relacionados con la frontera norte, representantes de ONGs presentes en la zona, así como con directores, editores y periodistas de medios locales, lectores de dichos medios, organizaciones y dirigentes comunitarios, y autoridades locales. Las mismas se realizaron durante diferentes viajes a la frontera entre los meses de abril y octubre de 2011.

Con la finalidad de conservar el anonimato de las fuentes, tal como nos fue expresamente requerido por los informantes, en los extractos de entrevistas que presentamos se usarán abreviaturas para dar cuenta de las voces de los distintos entrevistados, tales como DD para director de diario, OC para organizaciones comunitarias, DS para dirigentes sociales, PL para periodistas locales.

Esta investigación se apoyó, asimismo, en un corpus amplio de notas periodísticas, que se construyó teniendo en cuenta los hechos que marcaron el rumbo de las relaciones bilaterales entre Ecuador y Colombia entre los años 2008 y 2010. Así, se recogieron todas las coberturas relacionadas con el bombardeo de la fuerza aérea colombiana sobre el poblado ecuatoriano de Angostura ${ }^{1}$, hecho que volvió noticiable a la frontera norte de Ecuador.

Esas piezas fueron publicadas por seis periódicos: tres diarios nacionales, dos diarios provinciales y un diario local, entre el 1 de marzo de 2008, día del bombardeo, y el 31 de marzo de 2010, mes en el cual se conmemoraron en Ecuador dos años del acontecimiento. El corpus quedó integrado por 1.721 documentos informativos, interpretativos y de opinión extraídos de la prensa escrita y de internet, como explica el siguiente cuadro 1:

\begin{tabular}{|l|l|c|}
\hline \multicolumn{1}{|c|}{ ÁMBITO } & \multicolumn{1}{|c|}{ DIARIO/EDICIÓN } & TOTAL NOTICIAS \\
\hline \multirow{2}{*}{$\begin{array}{l}\text { ÁMBITO } \\
\text { NACIONAL }\end{array}$} & LA HORANACIONAL & 423 \\
\cline { 2 - 3 } & EL UNIVERSO & 471 \\
\cline { 2 - 3 } & EL COMERCIO & 484 \\
\hline ÁMBITO \\
PROVINCIAL & LA HORACARCHI & 109 \\
\cline { 2 - 3 } $\begin{array}{l}\text { ÁMBITO } \\
\text { LOCAL }\end{array}$ & LAORA ESMERALDAS & 19 \\
\hline
\end{tabular}

${ }^{1}$ El 1 de marzo de 2008 


\begin{tabular}{|r|c|}
\hline \multicolumn{1}{|c|}{ SUBTOTAL NOTICIAS } & 1587 \\
\hline \multicolumn{2}{|l|}{ NOTICIAS COMPLEMENTARIAS } \\
\hline $\begin{array}{l}\text { INTERNET: WEB LA HORA, WEB EL } \\
\text { UNIVERSO, WEB EL COMERCIO }\end{array}$ & 52 \\
\hline DIARIO EL TIEMPO DE COLOMBIA & 82 \\
\hline TOTALNOTICIAS & 1721 \\
\hline
\end{tabular}

Cuadro $\mathrm{N}^{\circ} 1$ : Composición del corpus analizado

Utilizando herramientas de la semiótica y del análisis de contenido, se interpretaron los significados dominantes en la construcción y uso de las noticias. Se realizó también un análisis comparativo entre las noticias provenientes de los tres tipos de medios analizados: medios/diarios impresos nacionales, provinciales y locales, y entre los resultados de este análisis y los obtenidos en las entrevistas y la observación etnográfica.

\section{Análisis y resultados}

\subsection{La frontera en las agendas mediáticas nacionales, provinciales y locales}

La producción de información sobre las fronteras ecuatorianas reconoce un punto de inflexión en el año 2000, cuando las acciones vinculadas al Plan Colombia se regionalizan, y por ello requieren para su implementación una suerte de "estructura interinstitucional" de la que participan el Estado, los países donantes, ONG nacionales y extranjeras y, para la cual se crean entidades específicamente vinculadas al cumplimiento de los objetivos del Plan (Guzmán, 2005: 113).

En ese marco emerge una perspectiva que permea los discursos e interpretaciones sobre la frontera colombo-ecuatoriana, proyectándola como un lugar caracterizado por la violencia, la inseguridad y el miedo. Este enfoque, al que denominaremos seguritario, se ha construido y posicionado como la perspectiva hegemónica para la comprensión de esta frontera, desde ámbitos tan distintos como los medios de comunicación, los estudios de consultoría producidos por entidades estatales, ONG y organismos multilaterales y, ha sido asimismo sustentada desde la reflexión académica.

A partir del bombardeo de Angostura y de la ruptura de relaciones diplomáticas entre Ecuador y Colombia, esta mirada seguritaria se ha consolidado, en virtud también del papel jugado por los medios nacionales. Miremos algunos resultados del análisis cuantitativo del corpus:

En el período estudiado, el tema que mereció mayor despliegue en los diarios $E l$ Comercio y El Universo fue el de las relaciones bilaterales entre los estados colombiano y ecuatoriano. Del total de piezas analizadas, el $40 \%$ correspondió a noticias al respecto. De este porcentaje, un 38\% apareció en primera plana. El segundo tema en importancia fue el narcotráfico, con un $37 \%$ de noticias publicadas, de las cuales el $45 \%$ fueron notas de tapa relacionadas con la incautación de cargamentos de droga presumiblemente destinados a salir del país.

En las ediciones provinciales de La Hora, la temática que recibió mayor cobertura fue la militarización del territorio fronterizo. Las noticias sobre acciones militares, operativos antinarcóticos e incautaciones de mercancías legales e ilegales en ambos lados de la frontera constituyen un $60 \%$ de las notas publicadas. De este total, un $48 \%$ apa- 
reció en primera plana. El tema siguiente en importancia fue el accionar de las guerri1las, en especial las Fuerzas Armadas Revolucionarias de Colombia, FARC. Un 25\% de noticias correspondió a este tema. De este porcentaje, un $40 \%$ fue nota de tapa.

En el diario local La Nación, los temas más abordados, con igual porcentaje de noticias publicadas, $40 \%$, fueron la inseguridad, con un $48 \%$ de notas en primera plana, y la economía local, con un $60 \%$ de publicaciones en tapa. El tema siguiente en importancia fue la acción del Estado en la frontera. Temas como la regulación de la venta de combustibles y los planes de fomento a la producción impulsados por el gobierno nacional ocuparon un $15 \%$ del total de noticias publicadas. De estas noticias, un $60 \%$ aparecieron en primera plana.

A partir de estos datos, sostenemos que la agenda fronteriza de los medios nacionales se compone de temas que tiene que ver con el posicionamiento del Ecuador en el orden regional. El interés predominante por las relaciones diplomáticas con Colombia a partir del ataque a Angostura y por la lucha en contra del narcotráfico parecería mostrar una frontera construida desde la óptica de las conflictivas relaciones internacionales.

Por su parte, la agenda de los medios provinciales evidencia un interés particular por el control del tránsito transfronterizo por parte de las fuerzas de seguridad. El reporte de los movimientos y acciones de la guerrilla colombiana puede ser interpretado, por ello, como otra expresión de un discurso mediático que describe la frontera norte desde una perspectiva militar.

Finalmente, en el diario local aparecen destacados tres temas que, según las evidencias recolectadas, los medios nacionales y provinciales no recogen sino marginalmente: el aumento de la inseguridad en los pueblos y ciudades de la frontera, el pequeño comercio local, y la acción del Estado. El despliegue informativo respecto a estas cuestiones parece llamar la atención sobre la postergación de la frontera en la política pública nacional.

\subsection{La prensa nacional: de espaldas a la población fronteriza}

El análisis de las representaciones dominantes que ofrecen los medios gráficos nacionales sobre las problemáticas fronterizas, pone de manifiesto la falta absoluta de participación de las poblaciones locales en la producción de la información que circula en el resto del país sobre las realidades de la frontera. Según hemos podido comprobar en nuestros recorridos por las provincias de Esmeraldas, Carchi y Sucumbíos, los fronterizos -sean éstos periodistas, autoridades gubernamentales, dirigentes comunitarios o ciudadanos comunes- no son quienes construyen esos relatos. Dicho de otro modo, la información que circula a través de los medios nacionales responde a imperativos y a lógicas ajenas a las dinámicas locales.

Esto se pone de manifiesto en la escasa diversificación de las fuentes utilizadas, y en la importancia otorgada a la perspectiva colombiana, emanada directamente del Palacio de Nariño. Es posible observar, además, la recurrencia de palabras-clave identificadas con el conflicto armado en Colombia y la agenda bilateral.

El problema de las fuentes en los diarios analizados responde a que la mayoría de medios ecuatorianos no producen fuentes propias sino marginalmente y, en general, 
solo para reforzar el enfoque espectacularizado de la información. Más del 70\% de las noticias responden a la reproducción de fuentes permanentes, como son las agencias internacionales. Es notable que, aun cuando los diarios ecuatorianos van asumiendo una postura cada vez más crítica con Colombia -especialmente en las notas de opinióny afianzan una posición nacionalista, en ningún momento dejan de nutrirse de las noticias de agencias que reproducen, de modo sorprendentemente textual, los comunicados del gobierno colombiano y las declaraciones de sus funcionarios.

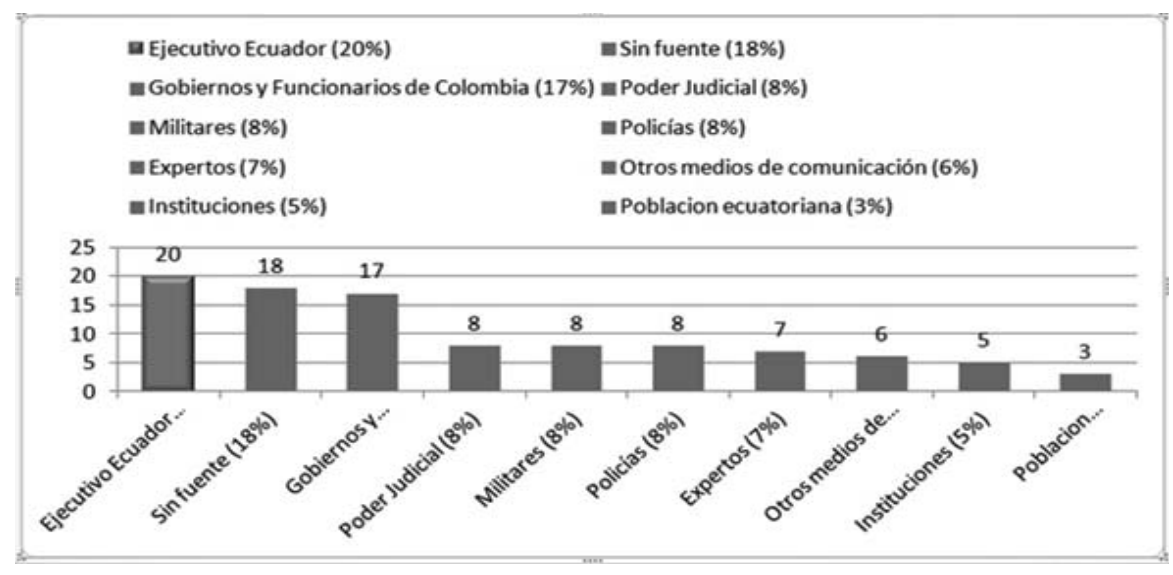

Cuadro $\mathrm{N}^{\circ}$ 2: Las fuentes de información de los medios nacionales

La postergación de la población fronteriza -a quien se consulta solo en el 3\% de las noticias- se pone de manifiesto, además, si se tiene en cuenta que en los artículos interpretativos, los periodistas usan como fuentes a especialistas en relaciones internacionales o en seguridad nacional, y en poquísimos casos -un $2 \%$ - se consulta a personalidades que hablen de las realidades locales en términos sociales, culturales o políticos.

En ese sentido es posible destacar que, aun cuando se utilicen varias fuentes en algunas noticias, éstas no sirven para reflejar perspectivas diversas, sino para que distintos actores contribuyan a producir el mismo horizonte de sentido desde distintos lugares de enunciación. Es decir, no se trata de distintas fuentes sino de una multiplicidad de personas e instituciones que asumen una misma vocería desde intereses diferentes. Esos son la OEA, los países vecinos, los embajadores, los organismos defensores de los derechos humanos, etc.

Otro dato destacable es el importante número de notas se aparecen sin fuente. El $18 \%$ contenido en el cuadro corresponde a todo el período estudiado pero, en algunos meses, este porcentaje ha llegado al 25 . La publicación de noticias sin fuente, además de contradecir los principios elementales del periodismo informativo, legitima la editorialización y eleva a la categoría de noticia la mera opinión de los periodistas.

En consonancia con este manejo de fuentes informativas, en las noticias aparecen, por una parte, las FARC, estigmatizadas casi siempre con la denominación de narcoterroristas, y luego, el gobierno colombiano, dos caras del mal en la saga de la sobe- 
ranía nacional. Al momento de identificar los enfoques de las noticias, queda evidenciado que las fuentes ecuatorianas y colombianas son las mismas, no solamente porque se privilegian los cables de las agencias internacionales informadas en Nariño, sino porque reproducen el mismo formato de telenovela política en donde hay villanos, víctima, cómplices y salvadores. La población local no cuenta como fuente, a menos que sirva para reproducir esta trama. De no ser así, aparece solamente como testigo de la saga, y en ningún momento como un vocero legítimo de una realidad compleja y desconocida.

Esta construcción ajena a las perspectivas locales también aparece cuando identificamos los significantes predominantes en las noticias analizadas, especialmente en los titulares:

\begin{tabular}{|c|c|c|c|c|c|c|c|}
\hline \multicolumn{7}{|c|}{ TITULARES SOBRE ANGOSTURA QUE NO MENCIONAN LA FRONTERA } \\
\hline & FARC & $\begin{array}{c}\text { PRESIDENTE } \\
\text { CORREA }\end{array}$ & $\begin{array}{c}\text { PRESIDENTE } \\
\text { URIBE }\end{array}$ & ATAQUE & PAZ & GUERRA & MEDIOS \\
\hline $\begin{array}{c}\text { LA HORA } \\
\text { NACIONAL }\end{array}$ & 60 & 25 & 15 & 6 & 7 & 7 & 3 \\
\hline EL UNIVERSO & 69 & 50 & 21 & 9 & 16 & 6 & 2 \\
\hline EL COMERCIO & 50 & 36 & 28 & 11 & 14 & 14 & 2 \\
\hline
\end{tabular}

\begin{tabular}{|c|c|c|c|c|c|c|c|}
\hline \multicolumn{7}{|c|}{ PALABRAS CLAVES EN LOS TITULARES QUE MENCIONAN LA FRONTERA } \\
\hline & $\begin{array}{c}\text { BLINDANE, } \\
\text { MILITARIZACIÓN, } \\
\text { SEGURIDAD }\end{array}$ & $\begin{array}{c}\text { POBLACIÓN } \\
\text { CIVIL }\end{array}$ & $\begin{array}{c}\text { PRESIDENTE } \\
\text { URIBE }\end{array}$ & EE.UU & PAZ & GUERRA & MEDIOS \\
\hline $\begin{array}{c}\text { LA HORA } \\
\text { NACIONAL }\end{array}$ & 18 & 11 & 15 & 6 & 7 & 7 & 3 \\
\hline EL UNIVERSO & 10 & 11 & 21 & 9 & 16 & 6 & 2 \\
\hline EL COMERCIO & 17 & 36 & 28 & 11 & 14 & 14 & 2 \\
\hline
\end{tabular}

Cuadros $\mathrm{N}^{\circ} 3$ y 4 : Titulares y palabras clave

La frontera representada en los titulares de la prensa nacional es una zona de guerra, ocupada por las FARC y, además, un objeto de negociación entre los jefes de estado de Ecuador y Colombia, con la intervención de los Estados Unidos. Los titulares no contienen una sola palabra que aluda a los fronterizos.

\subsection{Narrativas locales y representaciones mediáticas}

Nuestro trabajo de etnográfico puso en evidencia que la prensa de circulación nacional es fuertemente interpelada en las zonas de frontera porque sus agendas parecen ser impermeables a las demandas locales de información. Uno de los señalamientos más frecuentes es que estos medios no contienen temas de interés local, como los problemas que existen en todo el cordón fronterizo para la distribución de combustibles, los inconvenientes que ha traído la militarización de poblaciones pequeñas, y las restricciones que se impusieron al comercio transfronterizo a raíz del bombardeo a Angostura:

No se difunde lo que verdaderamente pasa en la provincia, sino lo que los medios consideran importante. Los medios no informan sobre nuestra realidad. Aquí no pasa lo que dice el diario $\mathrm{X}$, aquí solo pasa la necesidad (DD1). 
Los habitantes de la frontera destacan, asimismo, que la prensa debería contribuir a la cohesión social, a través de la difusión de "noticias positivas", es decir, de informaciones que destaquen los avances de las sociedades fronterizas en procura del bien común:

Lo que se debería difundir es lo que beneficia a la comunidad: las producciones vecinales, caminos que se han construido, el trabajo que hacemos en educación, las mejoras en salud. De ese modo los medios estarían contribuyendo al progreso. Habría más seguridad porque habría más actividades productivas de trabajo y disminuiría la violencia (Taller OC 1).

Cómo quisiéramos que los diarios hablasen de nuestros abuelos que eran gente alegre, cooperativista y solidaria, que compartía un plato de conchas, de la cultura del mangle. ¡Pero no!. Solamente se habla de la delincuencia en San Lorenzo, de los asaltos, de las armas, del arranche. Eso nos hace daño (Taller OC2).

Por el contrario, en los diarios nacionales se invisibilizan los procesos organizativos locales y sus demandas colectivas. Esto, según nuestros interlocutores, tendría que ver, primero, con la existencia de agendas informativas preestablecidas:

Cuando llegan corresponsales a la zona buscan una información muy concreta y nada más. Por lo general, la información que se busca es de crónica roja o tiene que ver con acciones militares (Taller OC1).

Los periodistas tienen ideas prefabricadas. Van hacia las organizaciones sociales con la idea de obtener solo la información que les interesa coyunturalmente, pero no profundizan en otros aspectos que se viven en la frontera. Hay temas que en las comunidades no están a la vista y los periodistas no se interesan en descubrir y conversar con la gente al respecto (Taller DS).

Esta falta de visibilidad se acentúa, en segundo lugar, porque los medios nacionales no incorporan las voces de la frontera:

No existe preocupación por investigar con seriedad y por conocer y recorrer las comunidades. Las noticias sobre la frontera no contienen entrevistas o testimonios de la gente (PL1).

Hay que generar otro marco y otra estructura de comunicación en donde tenga cabida el sector organizado, porque en los periódicos y en los canales nacionales no hay comunicación para y por las comunidades. De ese modo se lograría que lo que se cuenta no se cuente mal (PL2).

Los fronterizos denuncian, además, la representación estigmatizante y peyorativa que los medios nacionales hacen de sus realidades, de sus actividades productivas y de su cotidianidad:

Sería interesante que así como se informa sobre la violencia, se informe sobre otras cosas positivas que suceden en la frontera: cultura, música, desarrollo. Los medios de comunicación han considerado a la gente de la frontera como parte de "los malos" (Taller DC1).

Cuando los medios, incluso los provinciales, hablan sobre la juventud sobre todo la asocian a la violencia. Los dirigentes de organizaciones juveniles (que son muchas en la provincia) no tienen acceso a los medios de comunicación, porque los medios solo están interesados en los muertos, en la cantidad de droga incautada, y en si la gente tiene o no relaciones con la guerrilla (Taller OC1). 
Los medios nos han hecho un gran daño. Nos han "matado" con sus informaciones. Están matando el comercio, el turismo y la producción (Taller DS2).

Según se desprende de los testimonios recabados, esta falta de protagonismo de la población local y la desatención de los corresponsales de los medios nacionales hacia sus necesidades de información es una muestra de la discriminación que sufren los fronterizos. Como señaló un dirigente comunitario de Borbón, provincia de Esmeraldas: "Para los medios, no es igual la gente que vive en la frontera que la que no. Los medios informan sobre los que vivimos en la frontera como si fuéramos un virus" (Taller OC1).

La mirada construida desde los grandes centros urbanos es el efecto de un conjunto de condicionamientos y restricciones que los corresponsales de los medios nacionales en las zonas de frontera, tienen que aceptar para seguir trabajando, dado que, además, según comentarios realizados en reiteradas ocasiones, la mayoría de ellos cobra "por nota publicada".

Aquellos que han sido contratados en relación de dependencia denuncian, además, que sus salarios son sustancialmente menores que los que perciben quienes trabajan en las grandes ciudades, y que son evaluados "por productividad", es decir, por la cantidad de noticias que publican. La inseguridad y la precariedad laboral son una constante: "No tenemos estabilidad. Hoy tenemos trabajo, mañana no sabemos" (Taller PL3).

El corresponsal de provincia tiene que escribir sobre todo y hacer de todo. No somos periodistas especializados porque nos falta formación, pero también porque tenemos que hacer tareas administrativas, de limpieza, de mensajería y, además, tenemos que producir información general (Taller PL3).

Según se ha podido comprobar, estos corresponsales son, con poquísimas excepciones, oriundos de las provincias fronterizas, por lo cual conocen y comparten las insatisfacciones de la población local frente a los medios de comunicación denominados nacionales.

La demanda de información espectacular y de crónica roja es el condicionamiento más frecuente para el trabajo de los corresponsales de frontera:

El periodista de frontera está sometido a producir información espectacular, que venda. Eso es lo que nos piden desde Quito y Guayaquil. Los medios han creado también un gusto popular relacionado con el amarillismo. Lo que más nos piden son noticias policiales: de crímenes, de narcotráfico, de incautaciones, de contrabando. Entonces hay un círculo vicioso en el que el periodista no piensa en otros temas porque no cree que hay lectores para ellos, y el público consume temas amarillistas porque son los únicos que ofrecen los medios (Taller PL1).

La dificultad radica en escribir una noticia bien investigada, con la participación de otras fuentes, no solo de las oficiales, con datos interesantes, sin que nos despidan (Taller PL1).

Ante la constante demanda de noticias sobre situaciones conflictivas, los periodistas de frontera se ven obligados a buscar fuentes que pueden representar un riesgo 
para ellos. En estas circunstancias, los corresponsales no cuentan con garantías para su seguridad personal por parte de las empresas mediáticas:

"La seguridad es un tema que lo resuelve el propio periodista según su capacidad para descifrar el clima de seguridad o inseguridad en determinada misión informativa" (Ídem). "El periodista tiene que convertirse en árbitro de los problemas y, encima, nadie le garantiza nada. No hay protección" (Taller PL3).

\subsection{El enclave de producción de noticias sobre la frontera}

La población fronteriza y los productores locales de la información no influyen en los temas que se seleccionan para ser cubiertos, en las fuentes que se consultan ni en los enfoques informativos que desarrolla la prensa nacional. La construcción de los relatos mediáticos sobre la frontera prescinde de las preocupaciones, criterios y necesidades de los actores locales.

En un trabajo reciente sobre la economía de la coca y su consolidación a ambos lados de esta frontera, Espinosa (2009) propone una relectura del concepto de enclave, proveniente de teoría de la dependencia. Algunas de sus ideas al respecto, y las tensiones que este autor establece con los argumentos fundacionales de Furtado y Faletto, resultan de utilidad para proponer una caracterización de la producción informativa de los medios en torno a la frontera norte de Ecuador.

Si se toman en cuenta, por un lado, los señalamientos realizados por dirigentes sociales de la frontera, en el sentido de que la prensa nacional no aborda temas de interés local, invisibiliza sus demandas, difunde representaciones estigmatizantes sobre su vida cotidiana, y casi nunca incorpora voces locales, y por otro lado, los condicionamientos que impiden que los corresponsales estos medios aporten a la construcción de agendas temáticas, enfoques y perspectivas de cobertura de la frontera que se articulen localmente, podemos pensar que la construcción mediática de la frontera colomboecuatoriana responde a una lógica de enclave.

En este sentido proponemos pensar en una suerte de economía informacional gobernada por fuerzas, lógicas e imperativos localizados en centros nacionales de poder en la cual, como dice Espinosa citando a Cardoso y Faletto: "la producción es una prolongación directa de la economía central, porque las decisiones de inversión dependen del exterior y porque los beneficios (impuestos y salarios) apenas pasan por la nación dependiente" (Espinosa, 2009: 89).

La producción de información sobre la frontera se organiza desde un mercado centralizado en las redacciones de los medios nacionales, de donde emanan las decisiones sobre los modos de cobertura, los enfoques, la relevancia, pertinencia y oportunidad de los acontecimientos acerca de los cuales informan. La visibilidad de los actores fronterizos y de las situaciones de frontera en las que se inscriben sus prácticas y relaciones están sometidas a estos criterios. Si se tiene en cuenta, además, la precariedad laboral y la discriminación que denuncian los corresponsales locales, queda absolutamente claro que los beneficios materiales y simbólicos que proporciona la información periodística sobre la frontera, articulada a modo de enclave, "apenas pasan" por los pueblos y ciudades localizados en los límites con Colombia.

Esta caracterización del enclave de producción de noticias sobre la frontera como "dependiente y subordinada a los trusts o carteles que controlan la actividad econó- 
mica en la que emerge" (Ídem: 96) nos permite tomar en cuenta otra idea de este autor que puede resultar muy productiva para pensar en procesos de elaboración, gestión y circulación de información que surgen desde las resistencias locales y en oposición a la lógica del enclave. Según Espinosa, el enclave cocalero da lugar, y a la vez se apoya en un conjunto de acuerdos y vínculos entre los actores políticos que por el hecho de haber surgido en el marco de la correlación de fuerzas locales, permiten "sortear obstáculos" establecer negociaciones y apoyar los movimientos estratégicos de la población fronteriza frente a restricciones impuestas externamente (Espinosa, 2009). En las provincias fronterizas hemos constatado que existen prácticas que podrían ser consideradas como intentos de reapropiación de la producción informativa por parte de la población fronteriza. Las entendemos como esfuerzos locales por recuperar el protagonismo y la capacidad de decidir sobre qué decir, cómo hablar y a quiénes consultar sobre la frontera.

La característica que conecta a estas prácticas diversas es, precisamente, que se desarrollan con autonomía de los criterios y dinámicas que los medios de comunicación nacionales imponen a diario. Estas experiencias, que van desde la producción de información en espacios no periodísticos hasta la construcción, en los medios locales, de líneas editoriales gestionadas desde lógicas abiertamente opuestas a las tendencias que marcan los "grandes medios", son a la vez, el producto y la condición de permanencia de la dinámica del enclave informacional que instaló la prensa nacional en las provincias de frontera a partir de la implementación del Plan Colombia, y cuyas consecuencias se profundizaron luego del bombardeo a Angostura.

\subsection{Localización y heterotopía en la frontera: algunas reflexiones teóricas}

El análisis de la producción mediática de la frontera Ecuador - Colombia y sus repercusiones para la población allí asentada nos muestra aquello que Badiou (en Fischer, 2010) llama la localización y que irrumpe en la totalidad programática de la política para mostrar sus límites. El discurso de una autoridad de una provincia fronteriza resulta un discurso localizado con respecto al imperativo económico totalizante, por ejemplo, de la explotación minera que atraviesa varios niveles y discursos: el gubernamental (de corte político), el nacional (la idea de que el progreso económico puede vencer a la pobreza), el regional (los acuerdos con países de la región), el global (el interés del capital transnacional de extender sus zonas de influencia y explotación).

Esta localización se evidencia en el discurso del profesor C, de San Lorenzo, que explica cómo el pueblo afrodescendiente de la zona de San Lorenzo ha ido perdiendo sus tierras en un proceso de desterritorialización ligado al crecimiento de la palmicultura. El mismo explica que los primeros colonos ofrecieron dinero por la tierra y la gente empezó a venderla. Estos colonos comenzaron a contratar a los mismos afroecuatorianos que antes eran dueños de la tierra, quienes se convirtieron en peones del cultivo de la palma africana, por unos sueldos bajos y sin cobertura social:

Antes ellos eran dueños y transitaban libremente, ahora hay letreros que dicen: "prohibido el paso". Ahora caminamos por el pedazo de pavimento que nos dejan en el filo de las carreteras que construyen. Nos dejaron de peones en nuestra propia tierra. (profesor C) 
Esta narración explicita cómo el imperativo del progreso puede funcionar de modo perverso, retirándole a la gente lo que culturalmente le pertenece, la tierra, la selva, los ancestros, aquello que no es privatizable. Ese imperativo separa, además, lo ambiental de lo cultural, dado que los ríos sufren niveles de contaminación importantes, en la medida en que se ha aceptado que se trata de un costo del desarrollo, aunque afecte a las prácticas culturales y la microeconomía de toda la comunidad. Según nuestros informantes, la desterritorialización constante que sufren sus prácticas y sus poblaciones ha sido incorporada en forma fatalista al imaginario mismo de la frontera.

Cada uno de los puntos visitados muestra una realidad fronteriza distinta y nos hace repensar la frontera desde la localización y a partir de nuevas figuras. Retomemos los puntos que Bigo (2010) enumera cuando se pregunta por la frontera:

¿....es una línea continua que se cierra sobre sí misma y crea un espacio distinto que es posible homogeneizar, purificar, a partir de un centro de poder que tiene, como criterio central, la distinción clara entre lo interno y lo externo? ¿Es del tipo de una cinta de Moebius en donde el interno y el externo se distinguen pero varían de un observador a otro? ¿Es una serie de líneas punteadas, de límites, de puntos de contacto que producen una hibridación entre heterogeneidades no reductibles a una unidad? (Bigo, 2010: web, la traducción es nuestra).

Esas realidades heterogéneas a las que se refiere Bigo, cuya existencia contrasta con la homogeneidad que reflejan los medios, nos permiten decir que la frontera es un espacio heterotópico, que genera agujeros en donde las utopías son revividas a partir de diacronismos y escrituras subjetivas (Foucault, 1967). La heterotopía generaría un pliegue con respecto a la realidad dominante, abriendo un "espacio otro", un negativo, que localiza la utopía en un lugar. Ese lugar alberga tiempos alternativos y muchas veces divergentes: frente al tiempo de las transnacionales, el tiempo de la minería informal; frente al tiempo de la legislación migratoria, el tiempo de los pasos fronterizos ilegales; frente al tiempo del poder y la política mediática, la temporalidad de los periodistas locales y sus coberturas y prácticas de producción informativa.

Es preciso reconocer, sin embargo, que la frontera está atravesada por una normatividad que regula la economía y los intercambios legales e ilegales. Las relaciones de vecindad se adaptan a esos cambios normativos y dan forma a las relaciones de intercambio cultural y de reproducción social. Las personas no dejan de adaptarse a esas fronteras formales y reproducen formas de ciudadanía de bajísima intensidad, instituciones democráticas formales casi inexistentes, y condiciones para que un tercer espacio localizado sea posible.

A pesar de esto, las formas del poder dentro de la lógica capitalista pueden generar condiciones en donde ese tercer espacio no resulte posible: se trata de "archipiélagos de excepción" (Ramoneda, 2007), zonas bajo control de poderes transnacionales y globales que ejercen soberanía por encima de toda normatividad, sobre áreas como la extracción de materias primas, el fomento o la lucha contra el tráfico de armas y el narcotráfico. 


\section{Conclusiones. Estereotipo fronterizo y opinión pública}

Los imaginarios sociales y los referentes culturales no se construyen por fuera de las políticas, sino que por el contrario, temas tan generalizados en el interés público como la seguridad generan actitudes y regímenes discursivos que se tornan dominantes. Los medios, en el caso de las fronteras, operan como productores de discursos que legitiman las prácticas de seguridad (Rivera, 2012).

Los medios han construido un estereotipo de la frontera colombo-ecuatoriana ligado a la violencia del narcotráfico y la guerrilla, y a la clandestinidad. Sobre esta construcción operan algunos significantes: el vacío, el escondite; una lógica y un discurso ligados a la animalidad y a la cacería. La frontera, a pesar de su diversidad geográfica, es asociada con la selva y con lo natural. A eso se suma la disputa política por el interés ligado a los recursos naturales ubicados cerca de las zonas fronterizas. La frontera representada en la prensa nacional se transforma en un paisaje o en un campo de batalla, y esta operación la desubjetiviza, la construye como un lugar peligroso para la civilización y el progreso. Las dicotomías de civilización y barbarie, de dominación y colonialidad operan como categorías de representación casi exclusivas en las coberturas periodísticas sobre la frontera Ecuador-Colombia.

En este sentido, no podríamos plantear un debate sobre la responsabilidad social de los medios en términos individuales ni colectivos como lo planteaba McQuail (1993: 126-127) para una ética del periodismo. Nos encontramos, por el contrario, frente al análisis de las implicaciones del estereotipo en las relaciones sociales. Según explica Hall (1997: 325), el estereotipo enmascara las relaciones de dominación y poder que lo hacen posible, naturaliza su condición, y evita que se examinen las premisas que le dan lugar. Los estereotipos constituyen una forma de simplificación, que se expresa en general en términos binarios (por ejemplo, los colombianos son "malos" por contraste con los ecuatorianos que son "buenos"), y sirven para delimitar el ámbito de acción de ese otro a través de formas de control social y de discriminación. A partir del problema definido por Stuart Hall de la representación de un otro subalternizado, la estigmatización es una operación que parte de una relación de dominación o de colonialidad, en donde se intenta revertir un signo. En el caso de la población colombiana, la operación que se hace por parte de los medios es convertir a las víctimas (del conflicto colombiano) en victimarios, cómplices o encubridores.

Debido a su forma de representar a la frontera norte, la prensa gráfica ecuatoriana vuelve la espalda a su función social. En lugar de atender al interés general, se convierte en reproductora de ideologías y agendas preestablecidas por actores e intereses particulares. Los medios analizados faltan, además, a la promesa de volver cercano lo distante y familiar lo desconocido. No han asumido como propia la tarea de tender puentes entre los ecuatorianos de los grandes centros urbanos y aquellos que habitan en las fronteras y que, debido a ello, son marginados y estigmatizados. En ese sentido, no han aportado a la construcción de una identidad nacional incluyente.

La ideología dominante, generadora de estereotipos, esconde las relaciones de dependencia características de las sociedades poscoloniales, cuyos soportes predilectos resultan ser los medios masivos en la medida en que estos eviten la reflexión, la distancia crítica, la participación política, así como la representación de los movimien- 
tos sociales que expresan resistencias al estereotipo y a la subalternización. Los medios que tienden a la homogeneización de la opinión pública y garantizan la preservación del estereotipo, parecen haber encontrado su límite en la resistencia de las formas de organización local, y en los modos de hacer de un periodismo también local, cuyo horizonte es el sentido mismo de la vida social y de la práctica cultural.

\section{Referencias bibliográficas}

BAGLEY, Bruce; BONILLA, Adrián; y PÁEZ, Alexei (1991): La economía política del narcotráfico: el caso ecuatoriano. Quito, Flacso-North-South Center.

BIGO, Didier (2011):"Frontières, territoire, sécurité, souveraineté" en CERISCOPE Frontières. Disponible en http://ceriscope.sciences-po.fr/content/part1/frontieresterritoire-securite-souverainete [Fecha de consulta: 25/11/13]

BONILLA, Adrián (1993): Las sorprendentes virtudes de lo perverso: Ecuador y Narcotráfico en los 90. Quito, FLACSO-Abya-Yala-North South Center.

ESPINOSA, Roque (2009): "El enclave cocalero colombo ecuatoriano", en JARAMILLO, Grace: Construyendo puentes entre Ecuador y Colombia. Quito, FLACSO, pp. 81-127.

FISCHER, Daniel (2010): Notas. En "Que signifie « changer le monde»? ", Seminario de Alain Badiou (2010-2011). Disponible en http://www.entretemps.asso.fr/Badiou/10-11.htm_[Fecha de consulta: 27/11/13]

FOUCAULT, Michel (1967): "Des espaces autres", Conferencia pronunciada en el Centre d'Études architecturales el 14 de marzo de 1967. en Architecture, Mouvement, Continuité, Num 5, 46-49. Traducción al español: Gayo, Luis (1997). "Los espacios Otros" en Astrágalo, Num 7, pp 1-3. Disponible en: http://paisarquia.files .wordpress.com/2011/03/foucault-los-espacios-otros.pdf [Fecha de consulta: 27/11/13]

GIMÉNEZ, Gilberto (2007): "La frontera norte como representación y referente cultural en México" en Cultura y Representaciones sociales. Vol. 2, Núm. 3. 17-34. Disponible en: http://revistas.unam.mx/index.php/crs/article/view/16251 [Fecha de consulta: 27/11/13]

GRIMSON, Alejandro (2003): "Los procesos de fronterización: flujos, redes e historicidad", en GARCÍA, Inés: Fronteras, territorios y metáforas. Medellín, Hombre Nuevo Editores, pp 15-33.

GUZMÁN, Alicia (2005): Plan Colombia y asistencia internacional. Recreando el Estado en los Andes. Quito, Universidad Andina Simón Bolívar, Abya Yala, Corporación Editora Nacional.

HALL, Stuart (1997): Representation: cultural representations and signifying practices. London, Sage/ The Open University.

LINARES, María Dolores (2009): "Un puente en la zona transfronteriza: representaciones sociales, identidades y conflicto. El caso Posadas-Encarnación”, en Estudios 
Fronterizos, vol. 10, núm. 20, pp. 47-77. Disponible en http://www.redalyc.org/articulo.oa?id=53012159002 [Fecha de consulta: 26/11/13]

LUHMANN, Niklas (1998): Sistemas sociales: lineamientos para una teoría general. Barcelona, Anthropos. 1998, 445 pp.

MCQUAIL, Denis (1993): Introducción a las teorías de masas. México Distrito Federal, Paidós.

PÁEZ, Alexei (1991): "La inserción ecuatoriana en la dinámica andina del narcotráfico", en BAGLEY, Bruce; BONILLA, Adrián; \& PÁEZ, Alexei: La economía política del narcotráfico: el caso ecuatoriano. Quito, Flacso-North-South Center, pp. 142- 169.

RAMONEDA, Josep (2007): “Archipel d'exception”, en Cultures et conflits. Num. 68, pp 7-12.

RIVERA, Fredy (2012): La seguridad perversa. Politica, democracia y derechos humanos en Ecuador. 1998-2006. Quito (Ecuador), FLACSO-Ecuador.

VALENZUELA, José Manuel (2000): "Norteños Ayankados. Discurso y representaciones de la frontera", en Comunicación y Sociedad. Núm. 38, pp. 37-57. Disponible en: http://www.publicaciones.cucsh.udg.mx/pperiod/comsoc/pdf/38_2000 37-57.pdf [Fecha de consulta: 25/11/13] 